\title{
AL-HAMZAH WA ASHWAT AL-ILLAH BAINA AL-WASHFI AL-NUTHQI WA AL-BINYAH AL-MAQTHAIYYAH
}

\section{Musthafa Bani Dziyab, Mohammad Majid Al-Dakhil, Majdi Husain Ahmad Syahadaat}

\author{
majdi_faqeeh@yahoo.com
}

Depertement of Basic Sciences- Devision of the Arabic language and Literature Jordan- Irbid- Irbid University College (BAU)

\begin{abstract}
This study investigates the relation between the hamza and vowel sounds as it offers the phonetics' characteristics for both hamza and vowel sounds in their separatedly contexts and for the effect of phonetics' contexts on their phonetics' characteristics. This study concludes that there is a symmetrical relation between the characteristics of the hamza and vowel sounds specially when the vowel sounds come after (a) at the end of the word. In addition to what had been mentioned, this study elaborates the effect of syllabic structure in Arabic on the phonetics' sequences for the vowel sounds which lead to the convert of (w) and (y) to hamza after (a). This conversion is discussed despite the difficulties of the articulations of the sounds.
\end{abstract}

Keywords: hamzah, ashwat, al-illah, washfi al-nuthqi, binyah maqthaiyyah

الهمزة وهمسها، فذهب القدماء وعلى رأسهم سيبويه إلى أها

صوت مجهور، وأما المحدثون فقد وقفوا منها موقفين متقاربين:

الأول: يرى أها صوت لا هو بالمهموس ولا هو

بالمجهور، وذلك مراعاة لوضع الوترين الصوتيين في أثناء

نطقهما. وتبنى هذا الرأي كثير من المحدثين في مقدمتهم إبراهيم

أنيس (Anis،

(السعران، دت، دون الصفحة)، و كمال بشر وغيرهم. ويقول

كمال بشر - في معرض ردِّه على من يقول بكمس الممزة -:

إن الهمزة العربية لا يتّم نطقها بمرحلة واحدة تنفرج بعدها

الأوتار الصوتية، بل تتكون الهمزة ويتمٌٌ نطقها بمرحلتين

$$
\text { :Basyar) }
$$

الأولى: انطباق الوترين الصوتين، وفيها ينضغط الهواء

$$
\text { من خلفهما فينقطع النفس. }
$$

والأخرى: انفراج الوترينالصوتيين فجأة محدثا انفجارا

مسموعا. وهاتان المرحلتان متكاملتان، ولا يمكن الفصل بينهما

$$
\text { أو النظر إلى إحداهما دون الأخرى. }
$$

الهمزة صوت صامت حنجري شديد (وقفة Glottal

(stop

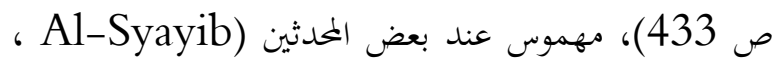

1999، ص 161) ويرجّح فريق ثالث من المحدثين أنه لا هو

بالمهموس ولا هو بالمجهور (Basyar)، 1986، ص 110)

وتخرج الهمزة من أول مدارج اللسان, ومن العرب من

يهمز،ومنهم من لا يهمز (ابن السكيت، دت، ص 158)

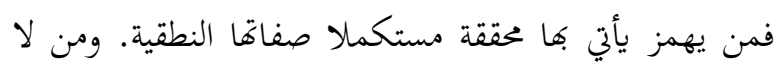

يهمز يفقدها بعض تلك الصفات، فتتحول إلى صور مختلفة، كأن تكون بين بين أو تنقلب إلى صوت من جنس الحركة قبلها، بمدّ الحركة مداً طبيعياً بمقدار حركتين تعويضاً عن الممزة، أو حذفها (Asir، 1994، ص 44 4) و قد اتفق العلماء قدماء ومحدثون على أن الممزة صوت شديد، واختلفوا في مخرجها، فهي عند (سيبويه) من أقصى الحلق (Sibawaih) ، 1982، ص 434)، وعند المحدثين من الحنجرة (Syahin)، 1980، ص 172). وقد اختلفوا بشأن جهر 


\section{الوصف النطقي لأصوات العلة}

هي أصوات مجهورة، ينطلق الهواء معها في مجرى مستمرّ حرّ، من خلال الحلق والفم, الذي يتشكل على نحو مختلف بفعل أوضاع الحلق واللسان والشفتين، وأبرز صفات

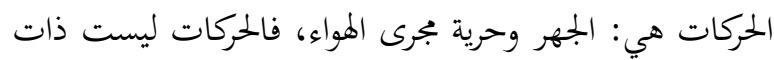

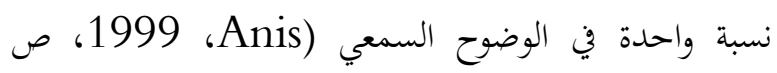

أما أصوات المد في العربية فهي: (الألف والواو والياء)

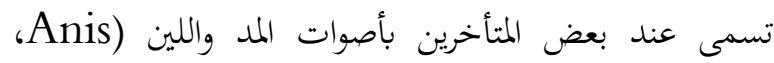
1999، ص 36، اسر، 1994، ص صند 53)، وعند غيرهم

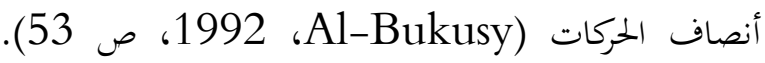

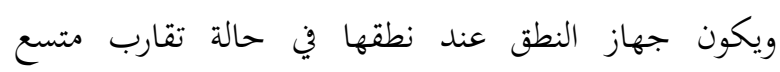

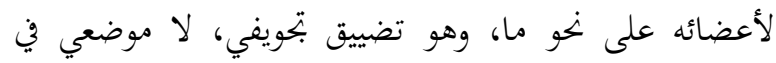

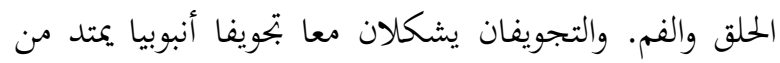
الحنجرة إلى الشفتين يسمى بالقناة النطقية، و يمثل اللسان

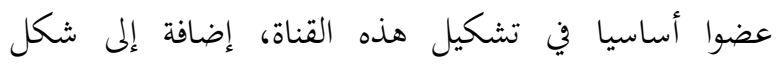

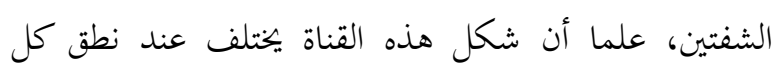

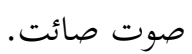
فالألف هو صوت مد ولين دائما، أما الواو والياء فلا نقصد بكما الأصوات الشبيهة بالصائتة، بل نعني بهما الواو والياء حريف المد واللين على نحو خاص. دليل ذلك أن الواو

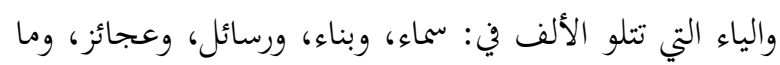

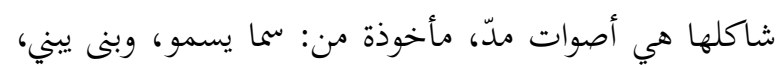

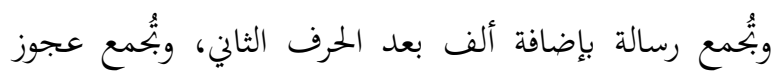
على عجاوز، فأصبحت " عجائز " بقلب الواو فيها إلى همزة.

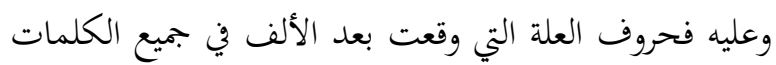

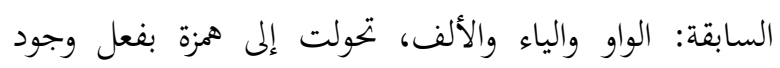
قاعدة صوتية تمنع توالي صوتين من أصوات العلة دون فاصل.

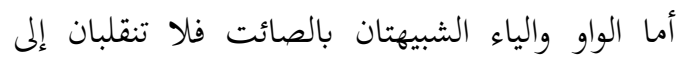
همزة، في مثل كلمة سماوات، وبنايات، وقساور جمع قسورة،

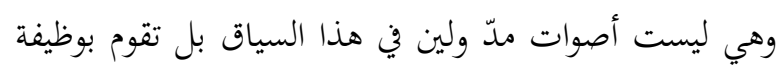

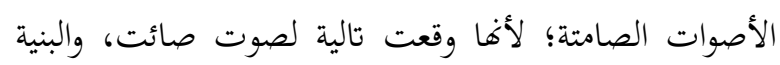

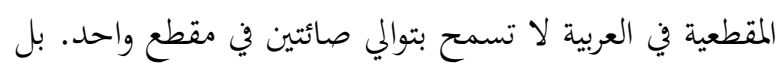

فهو بذلك يرأن المرحلة الأولى هي الأهم في تكوين الهمزة من المرحلة الثانية، ومن ثم كانت تسميتها بكمزة القطع. الثاني: يقول بهمس الهمزة لعدم تذبذب الوترين الصوتيين معها؛ لأنه يستحيل أن ينتج في وقت واحد انفجار

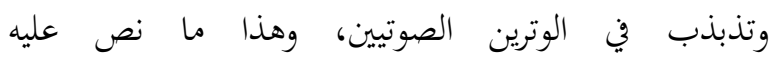

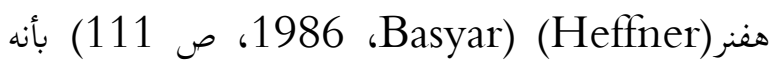
صوت مهموس دائما. وأخذ بهذا عبد الرحمن أيوب، و غيره

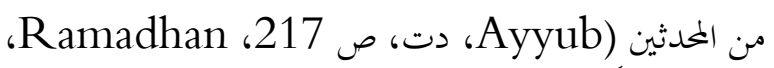

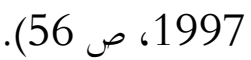
وبناء عل ما سبق لا يظهراختلاف جوهري في وصف صلف

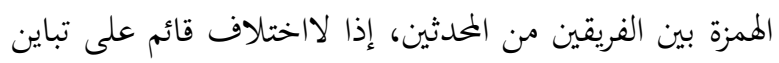

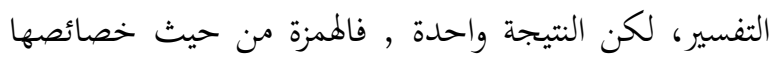
الصوتية مهموسة لعدم تذبذب الوترين الصوتيين عند النطق كها، وهو الرأي الذي يتبناه عدد من الحدثين على الرغم من لعدئ.

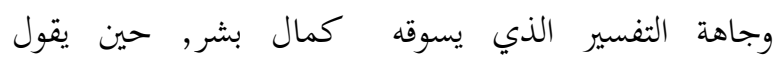
Basyar عن عدم التذبذب وحده , بل ينتج عن الإقفال التام للوترين،

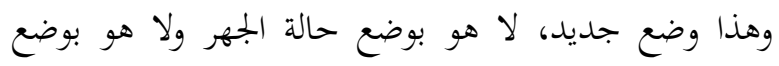
فالهمزة تتميز عن غيرها من الأصوات بأن الوترين

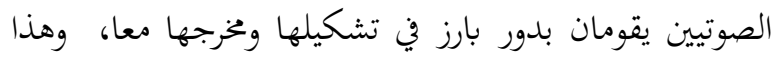

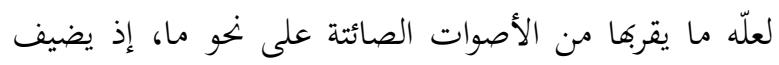

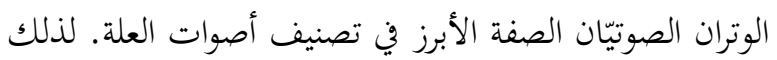
فمن المستحيل أن ينتج في وقت واحد انفجار وتذبذب في الوترين الصوتيين. والهمزة بحسب طبيعة نطقها، وبُعد مخرجها تُعدّ أصعب الأصوات نطقاً، وأكثرها إجهادا. ويرى بعض المتأخرين أنه في أثناء عملية نطق الهمزة إنها، يكون وضع الوترين الصوتيين بصورة مشدودة، بحيث يتم فيها إغلاق المزمار إغلاقا تاما، وغالبا ما يكون أحد الطرفين متداخلا مع الآخر، فينحبس الهواء خلف الوترين الصوتيين 1999 Al-Syayib) 
المجموعة الأولى: تشمل أصوات اللين الضيقة (Close) الكسرة والضمة (i، (i، وما قَرُب منهما.

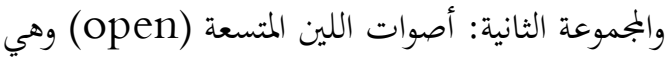
الألف(9) والفتحة (a) وما قَرُب منها.

\section{علاقة الممزة بحروف العلة}

إن جَمْعَ القدماء للهمزة مع حروف العلة، ووصفها بأنها

هوائية أو من أصوات أقصى الحلق (Sibawaih،

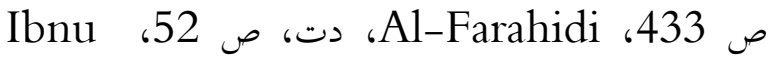
Jinni

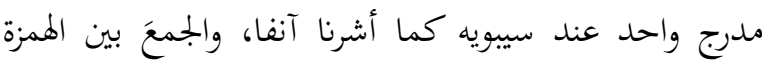
والواو والياء والألف في باب الإعلال؛ يَشي بعلاقة من نوع ما بين الهمزة وحروف العلة، وهو ما جعلنا نبحث في خصائص كلِّ منها؛ لنتبيّن إنْ كان هناك علاقة من المماثلة أو المخالفة.

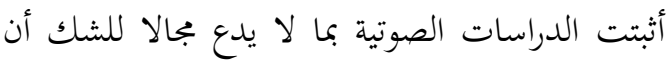
الهمزة من الصوامت وحروف العلة من الصوائت، وهاتان طائفتان مختلفتان عند أغلب اللغويين. كما أن الهمزة يُقُطَع بأها ليست مجهورة بأي حال من الأحوال بإجماع اللغويين المحدثين وأصوات العلة مجهورة في كل اللغاتأما الأصوات الصائتة فهي أطول من الأصوات الصامتة عادة (Anis)،

$$
\text { 1999، ص 78، Basyar، }
$$

إن الخصائص الفردية للهمزة ولأصوات المد واللين

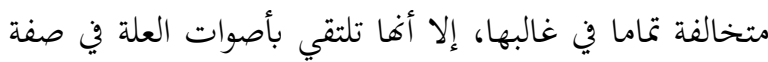

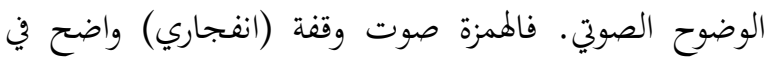

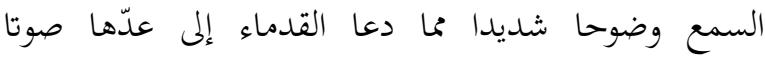

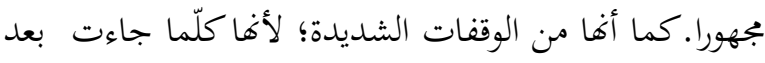
صوت آخر فإنها تفصله عنه بشكل فجائي (Al-Khauli)،

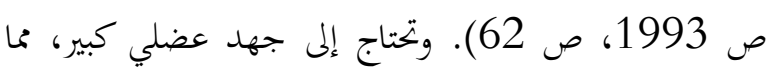
يزيد في وضوحها السمعي (Dl-Syayib)

أما الممزة باعتبار مخرجها فهي أدخل أصوات جهاز النطق في الجوف، وهي صوت حنجري، وعلى الرغم مما يراه
نميل إلى القول بأن البنية الصوتية للواو والياء، المدّ واللين، في المفرد قد تحولتا إلى صوتين شبيهين بالصائت، يقوم بوظيفة الصوت الصامت لوقوعه بين صوتي مد ولين، وهما الألف التي قبل الواو والتي بعدها أو الياء في كلمتي: سماوات، وبنايات؛ وذلك لأن الواو والياء في ظاهر الوصف الصوتي تنتميان إلى

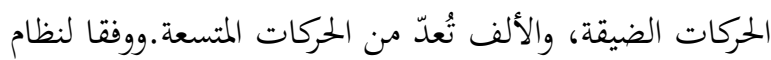
الحركات المعيارية، فهناك تقابل واضح في موضع اللسان في تهن منطقة نطق الحركات. انظر الرسم الآتي (Anis،

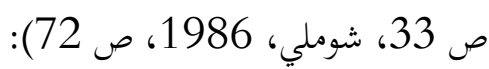

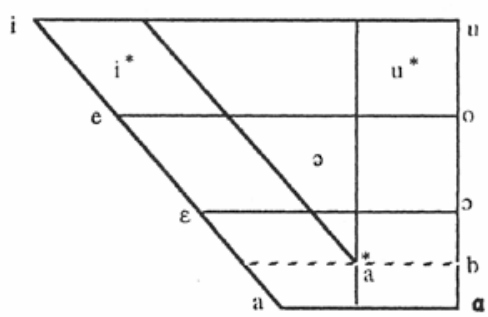

فالألف تقابل الواو والياء، ويُعدّ هذا من باب المخالفة الصوتية. والانتقال من منطقة الحركات الضيقة إلى منطقة الحركات المتسعة الذي يُعين على الفصاحة والوضوح في تهني النطق، ويُمُكِّن من نطقها بتمام صفاتها سواء أكانتُ أصواتا صائتة أمأصواتاشبه صائتة، دون اللجوء إلى الإبدال الصوتي بنداء بالانتقال إلى صوت صامتٍ محض كالهمزة؛ لما تشكله من صعوبة نطقية واستثقال. بل تتيح الآلية النطقية تحويلَ الصوت الصائت إلى صوت شبيه بالصائت، يقترب في خصائصه

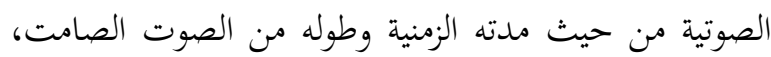

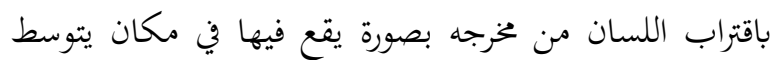
فيه بين الصوت الصائت والصامت. فتقوم الواو والياء الشبيهتان بالصائت بوظيفة الصوت الصامت، وتتيح الفرصة

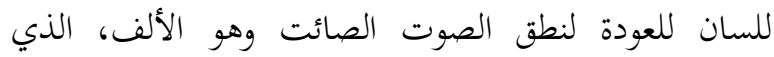
يخالف في وضعه النطقي في التجويف الفموي صوتي الواو

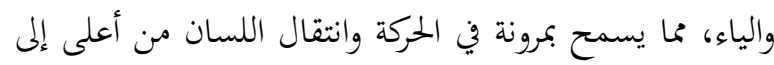
أسفل ثم إلى أعلى دون استثقال أو مشقة أو جهد كبير. تقسّم أصوات اللين إلى مجموعتين (Anis، 
واجتماع الوترين الصوتيين، وهذا تعويق كامل، ينضغط معه

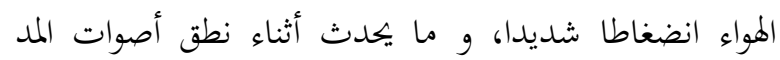

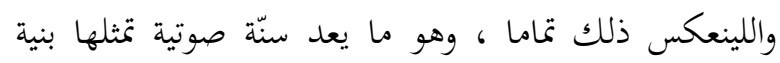

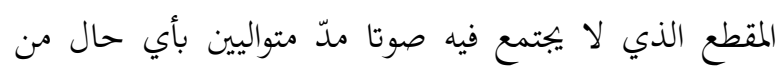
الأحوال.

إن المخالفة الصوتية في الحقيقة تشكل جوهر العلاقة بين حروف المد والهمزة. فالمخالفة الصوتية قانون صوتي لغوي يضبط توزيع الأصوات في السلاسل الصوتية المنطوقة، ليستبعد

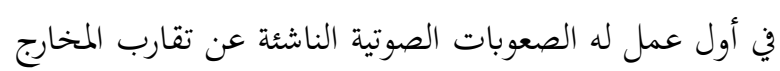

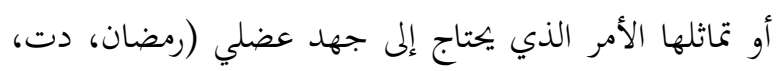

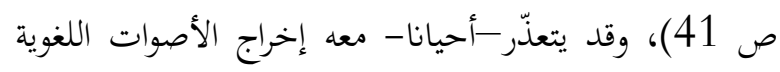

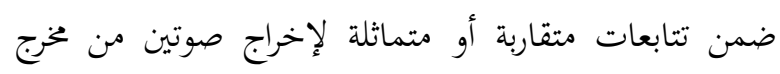

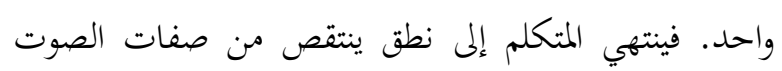

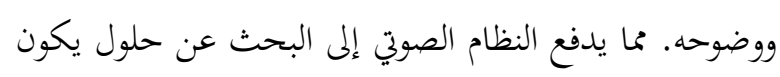

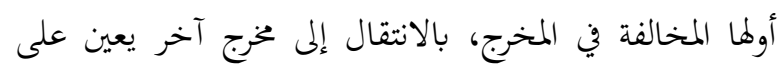
النطق الفصيح السليم. والذي يستكمل فيه جهاز النطق أداءه

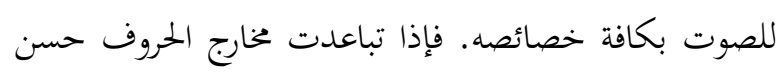
تأليفها وإذا تقاربت لجأ النظام الصوتي إلى المخالفة الصوتية

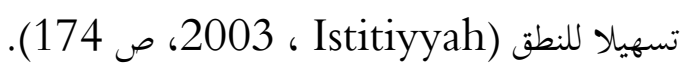

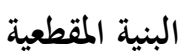

يعرف المقطع بأنه:( أصغر وحدة صوتية يمكن النطق ها، ويستطيع المتكلم أن ينتقل منها إلى غيرها من من أجزاء

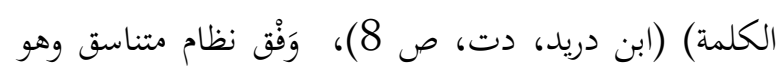
الوحدة الصغرى؛ لأنه يرفض تقسيم الكم المتصل إلى أصوات، دات

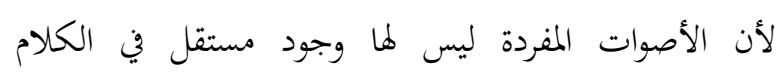
1996، Hilal)

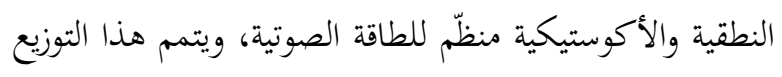
على أساس التباين الكائن بين الصوامت والحركات وأنصاف

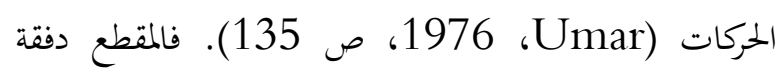
صوتية متناسقة مكونة من صوامت وصوائت جعلها إبراهيم أنيس في خمسة أشكال , و حدد له بعض الصفات التي تميز
كمال بشر من وجود اضطراب _ عند الأوائل في تحديد مخرج

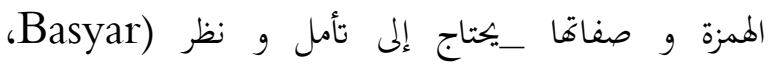
1986، ص 114 و 288)، إلا أغم يشيرون بصورة ما إلى إلى صلة صوتية نطقية ووظيفية تربط بين الهمزة وحروف العلة، سواء أكان ذلك من حيث خصائصها النطقية صوتا مفردا, أم من حيث سياقاتًا الصوتية في البنية المقطعية. أو حتى للطبيعة

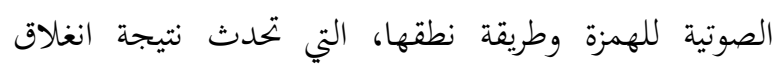
الحنجرة بسبب اجتماع الوترين الصوتيين، فيتولد ضغط كبير خلفها ما يلبث أن ينفك محدثا فرقعة شديدة (Basyar)،

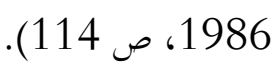
علما أن للهمزة حكما يخالف جميع الأصوات، لأهما صوت لا هو بالمجهور ولا هو بالمهموس، وعملية النطق بها

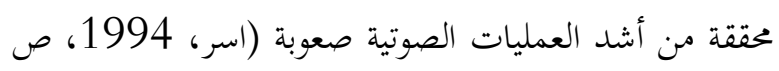
42، Anis،

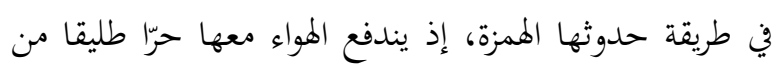

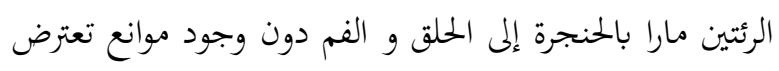

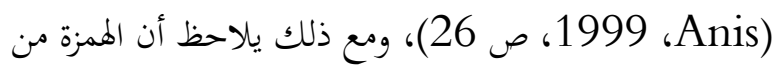

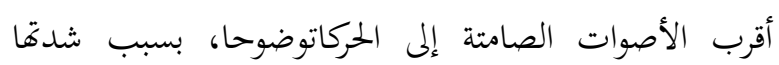

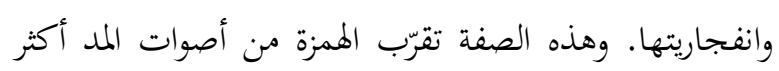

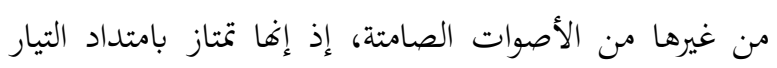

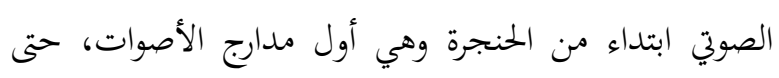

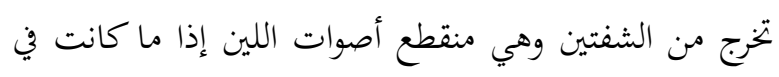
البنية المقطعية التي سوف نعرض لها فيما يأتي.

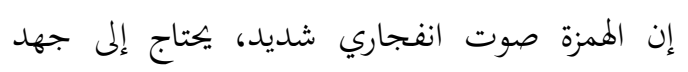

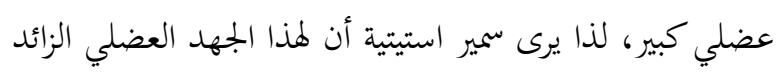
أثر في زيادة الوضوح السمعي للصوت (20) Istitiyyah) ، 2003، ص 206). مما يقرب الهمزة من حيث الوضوح السمعي إلى أصوات المد. وربما هذا ما دعا القدماء إلى اعتبار

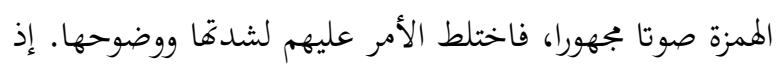

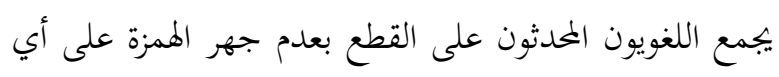

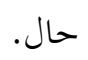

وعليه يلاحظ أن صوت الهمزة يمثل مخالفة صوتية صريحة لأصوات المد واللين, فنطقها يتطلب انسداد الحنجرة 
يقترب فيه اللسان من الطبق في منطقة متوسطة بين نطق الواو

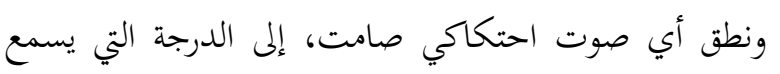

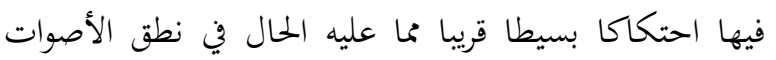

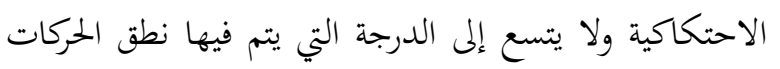

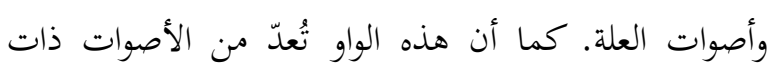

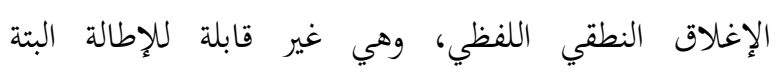
Istitiyyah) المقطعية في العربية كما سنبين ذلك فيما يأتي:

البنية المقطعية للكلمة العربية وانقلاب حروف العلة إلى همزة.

و لبيان التغيرات الصوتية التي تصيب الكلمة وتحدث تغيرا في بنية المقطع في الكلمة العربية، سوف نتناول بالتحليل المقاطع التي انقلبت فيها الواو والياء هزة، في مثل سماء، وبناء.

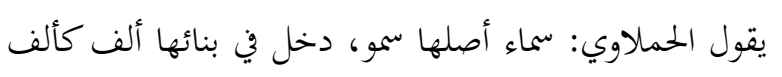
كتاب (Al-Syayib) افتراضا(سماو). فعلى هذا الافتراض تكون البنية المقطعية

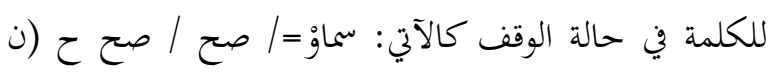
ح)، يُقصد بـ (ن ح) نصف حركة. أما في حالة تحريك

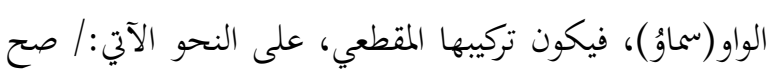

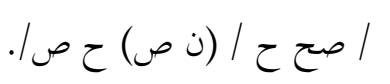

فالبنية المقطعية للمقطع الأخير للكلمة (سماو): / لمي

حالة الوقف يخالف تصنيف إبراهيم أنيس، ولا يوافق البنية

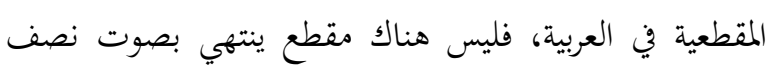
صامت أو نصف حركة، فيما أورده سواء من المقاطع المفتوحة

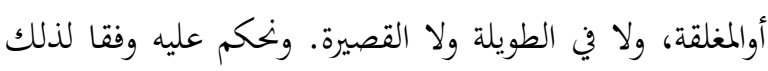

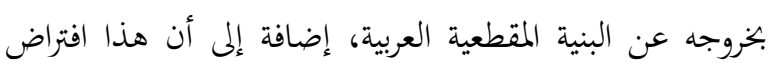

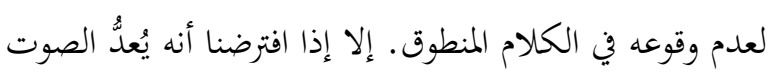
المسمّى نصف الصامت كالصوت الصامت؛ أو لأنه يشغل وظيفة الصوت الصامت في البنية المقطعية للكلمة العربية.

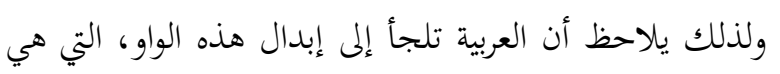
واو للمد في كلمة (يسمو)، ونصف صامت في كلمة (سمَمَ) كممزة. وعندها يصبح التشكيل المقطعي للكلمة بعد الإبدال

$$
\begin{aligned}
& \text { ظهورها في نسج الكلمات العربية (Anis، 1999، ص } \\
& \text { 1 _ صوت ساكن + صوت لين قصير. ( ص ح ) ) }
\end{aligned}
$$

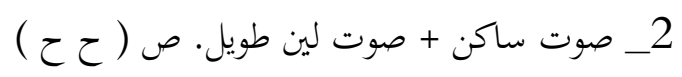

$$
\begin{aligned}
& \text { 3_ صوت ساكن + صوت لين قصير +صوت ساكن } \\
& \text { (ص ص (ص ) }
\end{aligned}
$$

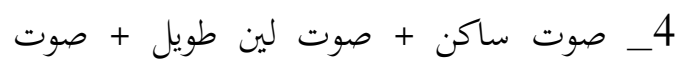

$$
\begin{aligned}
& \text { ساكن. ( ص ح حص ) } \\
& \text { 5_ صوت ساكن + صوت لين قصير + صوتان } \\
& \text { ساكنان.( ص ح ص ص ) مصن }
\end{aligned}
$$

ويُلاحظ أن وصف علماء اللغة إلى تشكيل المقطع في العربية من الجانب الأكوستيكي يقوم على تحديد فهايتها، فإنان

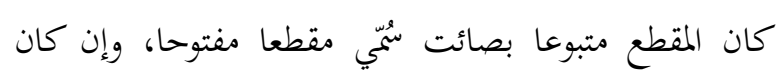

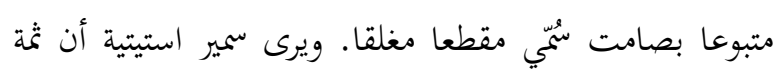
مقاطع في اللغة لا يصح أن توصف بأها مفتوحةمع أها في

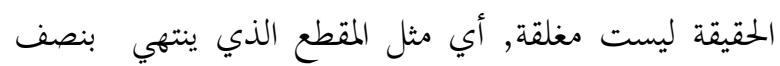
حركة،وذلك مثل \} لو \{\{. فالموجة التي تتشكل عند نطق الواو

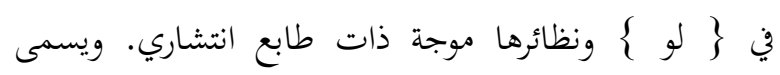
المقطع المنتهي بنصف حركة بأنه مقطع نصف مفت مفتوح (Istitiyyah) وتبدو ملاحظة سمير استيتية جديدة تثير الاهتمام ,لأن من شأها أن تفسر لنا تغيّرات صوتية مهمة في بنية الكلمة وبناء مقاطعها. وخاصة عندما تحتاج بنية الكلمة المقطعية والصوتية إلى تحولات من نوع انقلاب أصوات المد الواو والياء

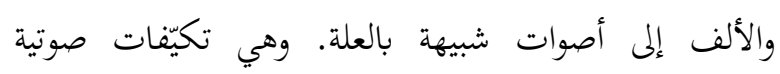

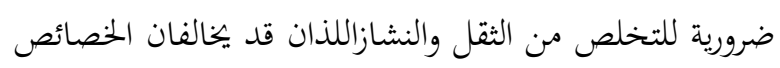

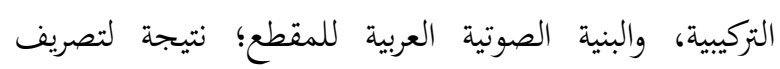
الكلمة بزيادة لواحق إليها، كما في كلمة (سماوات جمع سماء).

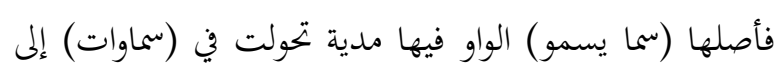

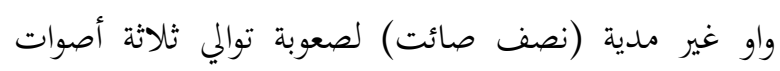

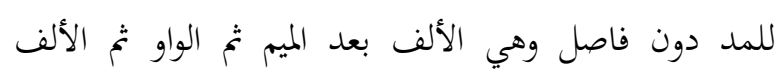

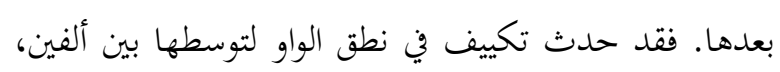


أولا: لا بدَ أن يكون هذا الصوت صوتا صامتا ليوافق

بنية المقطع في العربية، إذ يمتنع أن يتعاقب صوتا لين في مقطع واحد في العربية مطلقا.

ثانيا: إن الطبيعة الصوتية لأصوات المدّ تتطلب أن إنهاب

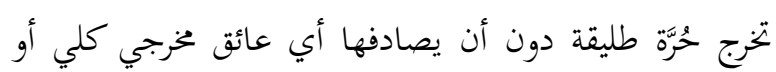
جزئي. وهنا يجدر بنا أن نشير إلى أن أول المدارج الصوتية التي تصادف تيار الهواء المنشئ للأصوات الصامتة هو الحنجرة.

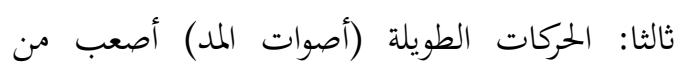

الأصوات الصامتة في النطق، وإنّ تتابعها يمثل صعوبة نطقية يفرٌ منها التشكيل الصوتي والمقطعي في العربية، على النحو الذي رأيناه في التشكيل المقطعي الذي انتهى إليه إبراهيمأنيس.

ومن خصائص أصوات المدّ كما وصفها القدماء أها

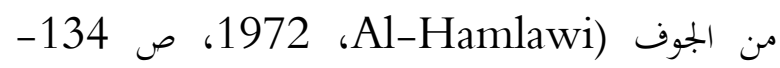
135)، وأقرب المخارج إلى الجوف وأولها الحنجرة، ويخرج منها

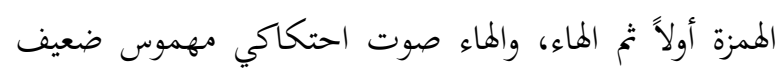

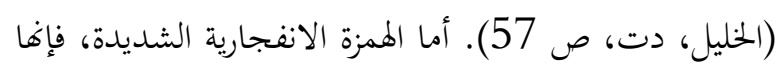
تمثل الحل الأمثل لقطع صوت اللين في البنية المقطعية لكلمتي (سماء وبناء) وما شاكلهما في المقطع الثاني منهما، والمكون من صوت ساكن + صوت لين قصير. والمقطع الثالث يماثله تماما. يترتب على ذلك وقوع الألف الزائدة التي تشبه الألف

في كلمة (كتاب)، في مثل كلمتي (سماء وبناء)، اختلاف التركيب المقطعي؛ ليصبح المقطعان الثاني والثالث على صورة مقطع واحد، فتقوم الحنجرة عن طريق انسدادها بتقارب الوترين الصوتيين بقطع امتداد صوت الألف، لأنه أطول أصوات المد فتتشكل الهمزة، الذي تحل فيه صوتيا محل صوت المدّ الثاني أو نصف الحركة، وهو الواو أو الياء. وبهذا تصبح البنية المقطعية موافقة لمقاطع العربية على الصورة الآتية (صوت ساكن + صوت لين طويل + صوت ساكن)، وهو المقطع الرابع في تصنيف إبراهيم أنيس. وهذه البنية الجديدة التي

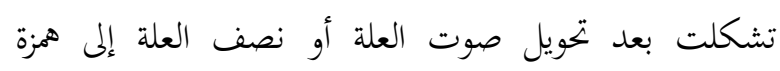
بسبب الطبيعة العضوية لنطق الأصوات، إضافة إلى خصائص

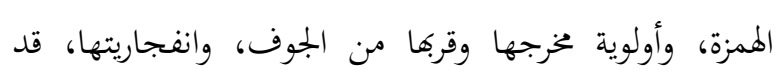

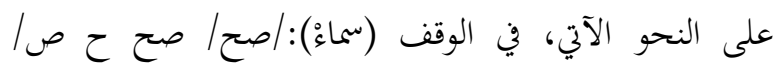
فالمقطع الأول قصير مفتوح، والمقطع الثاني طويل مغلق.

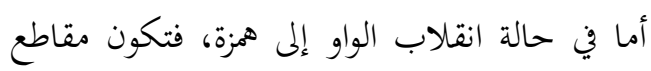

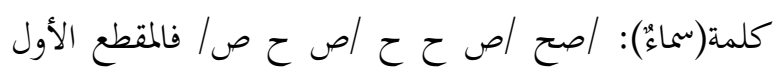

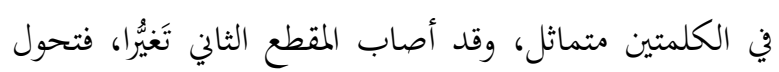

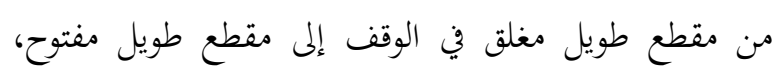

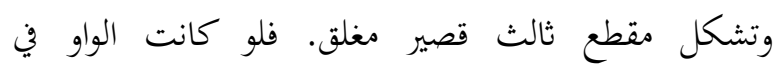

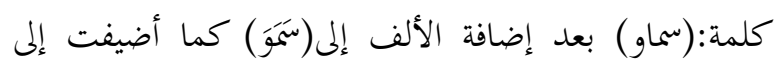

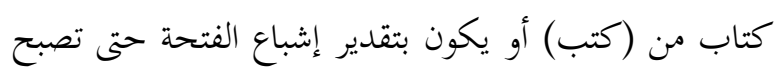

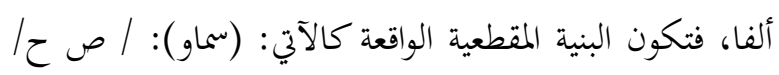

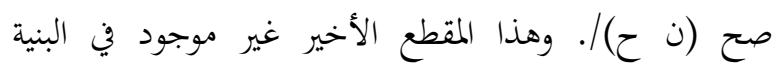

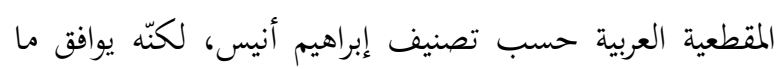

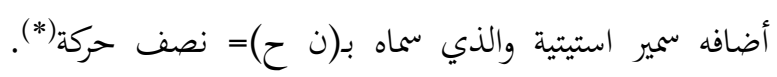

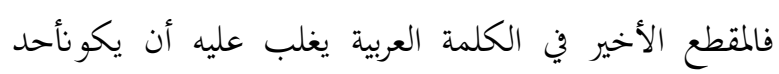
مقطعين، بحسب التصنيف السابق، هما:

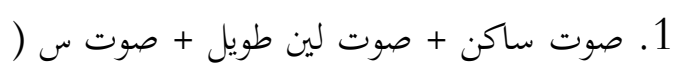

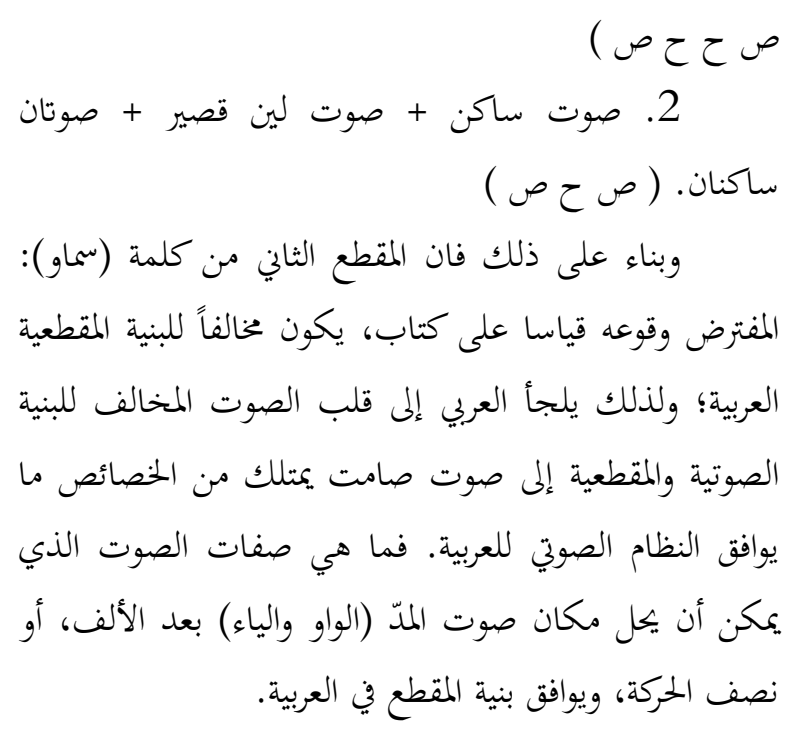
(*) ن ح = نصف حركة، ونغضل أن تكون تسميته بنصف صامت؛ لأن التصويت

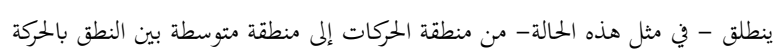

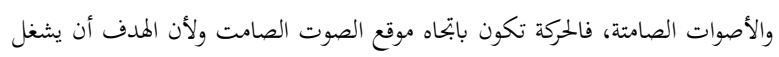

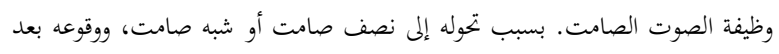




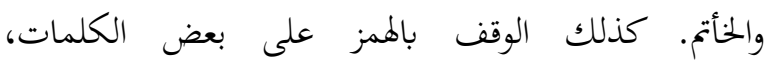

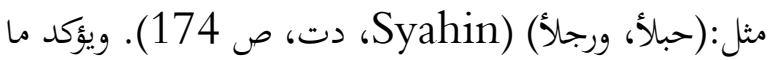
هذا ما يراه عبد الواحد وافي في حديثه عن التفاعل بين أصوات اللين، إذ يقول: إن"بحاور صوتي لين أو تقاربمما في

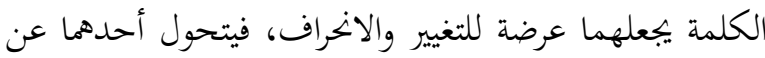

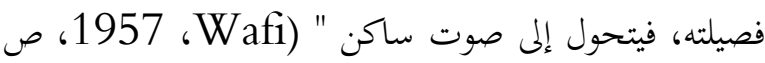
274-275 أو شبيه بالصامت.

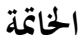

بيّن البحث خصائص كل من الهمزة وحروف العلة،

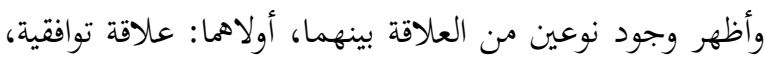
تتمثل في الوضوح وأولية المخرج. وثانيهما: علاقة المخالفة التي تصني تمثلت بتصنيف الممزة صوتا صامتا، وحروف العلة أصواتا

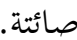

وبيّن البحث كذلك الخصائص والتصنيفات المقطعية في العربية وما يجري عليها من تحوّلاتٍ، تمدف إلى التخلص من

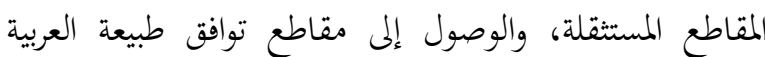
الصوتية، من خلال وصف أكوستيكي لطبيعة عملية النطق، وَفْقًا للخصائص الصوتية للتنابعات المقبولة في المقطع الأخير في الكلمة، على نهو خاص في العربية وَفْقًا لدراسات إبراهيم أنيس، وكمال بشر، وكذلك سمير استيتية وآخرون. وانتهى البحث إلى أن هذا التحول من حروف العلة

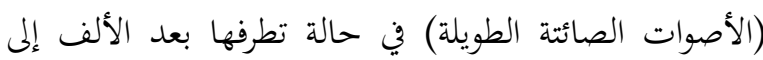

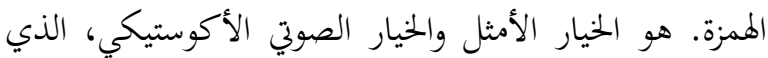
يوافق الصيغة الصوتية والمقطعية العربية، ويجعل الهمزة بخصائصها في شدقا وانفجاريتها، هي الخيار الأوحد الملائم. وهو ما يؤكد صفتها كصوت صامت، ويخرجها من دائرة حروف العلة.

وأثبت البحث أن انقلاب الواو والياء وكذلك الألف إلى هزة تؤيّده البنية المقطعية في الكلمة العربية، وهو ضرورة حتمية في هذه السياقات الصوتية موضع الدراسة، وأن انقلاب أحرف العلة هزة لا يجعل الهمزة من حروف العلة على أيّّ
رشّحها للقيام بتشكيل جديد للبنية المقطعية للكلمة، لتوافق

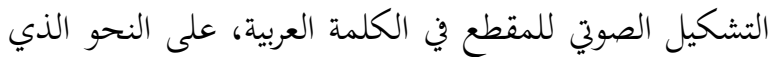
رأينا.

ومن الملاحظات التي تجعل الهمزة أفضل الخيارات في وقوعها موقع العلة مع أها صوت صامت , ظهور حالة امتزاج

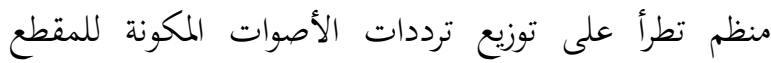

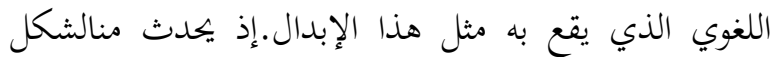
الجديد للمقطع بعد دخول الهمزة توافق في ترددات نسيجه اللغوي , لينجم عن ذلك التوافق تركيب مقاطع مقبولة الإيقاع لدى أبناء العربية (Al-Syayib، 1999، صن من 162)، على النحو الذي دعت إليه الحاجة الصوتية لإحلال الهمزة

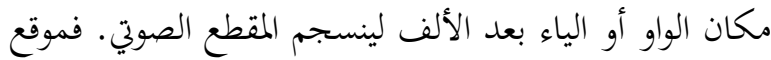
الصوت يعرضه لكثير من التطور والانخراف، فأصوات اللين المتطرفة يجعلها في الغالب عرضة للسقوط ويؤدي أحيانا إلى تحولها إلى أصوات أخرى (Istitiyah، 2003، صنس صن

واللغة العربية تميل عادة في مقاطعها إلى المقاطع الساكنة، وهي التي تنتهي بصوت ساكن، ويقلّ فيها توالي المقاطع المتحركة،خصوصا حين تشتمل على أصوات لين قصيرة W Wafi) الحركات التي تقع قبل الهمزة تتصف بأنّ درجتها طويلة جدا Al-Syayib) زاد ذلك في طوها، مما يدعو إلى إهاء هذه الإطالة إلى صوت يتصف بالقطع والوقف والشدَة، فيفضي حسيراً إلى مخرج الهمزة 191-Syayib) الخيار الصوتي المفضل في مثل هذا التركيب الصوتي والمقطعي؛

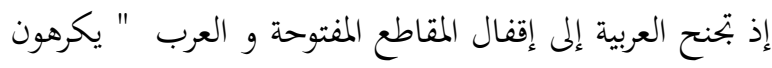

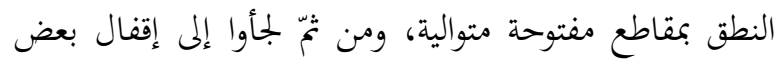

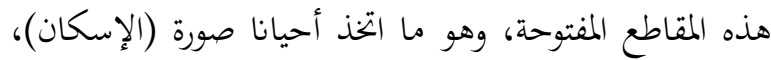

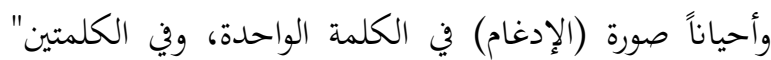
(8-7 2000، Ibnu Jinni) ولعل ظاهرة الهمز هي إحدى ظواهر جنوح العربية إلى إقفال بعض هذه المقاطع المفتوحة، وذلك نحو قولنا: العألم 


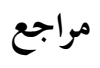

Abdu al-Tawwab, Ramadhan. Al-Tathawwur al-Lughawi. Qahirah: al-Khanji.

Abdu al-Tawwab, Ramadhan. (1997). Al-Madkhal ila Ilm al-Lughah wa Manahij al-Bahts al-Lughawi. Thaba'ah Tsalitsah. Qahirah: al-Khanji.

Al-Bukusy, al-Thayyib. (1992). Al-Tashrif al-Arabi. Taqdim: Shaleh al-Qurmadi.

Al-Farahidi, Khalil bin Ahmad. (1980). Al-'Ain. Tahqiq: Mahdi al-Makhzumi. Baghdad: Dar al-Rasyid li al-Nasyr.

Al-Hamlawi, Ahmad. Syadza al-Urf fi Fan al-Sharf. Thaba'ah Tasi'ata Asyar. Qahirah: Maktabah Musthafa al-Babi al-Halbi.

Al-Kana'anah, Abdullah. (1997). Atsru al-Harakah al-Mazdujah fi Bunyah al-Kalimah al-Arabiyyah. Thaba'ah Ula. Oman: Wizarah al-Tsaqafah.

Al-Khauli, Muhammad Ali. (1993). Madkhal ila Ilm al-Lughah. Thaba'ah Ula. Oman: Dar al-Falah li al-Nasyr.

Al-Syayib, Fauzi. (1999). Muhadharat fi al-Siyasah. Thaba'ah Ula. Al-Urdun: Mansyurat Wizarah alTsaqafah.

Anis, Ibrahim. (1992). Fi al-Lahajat al-Arabiyyah. Thaba'ah Tsaminah. Qahirah: Maktabah al-Anjalu al-Misriyyah.

Bergstrasr. (1994). Al-Tathawwur al-Nahwi li al-Lughah al-Arabiyyah. Thaba'ah Tsaniyyah. Qahirah: Maktabah al-Khanji.

Basyar, Kama. Al-Aswat al-Arabiyyah. Qahirah: Maktabah al-Syabab.

Hasan, Tamam.(1955). Manahij al-Bahts fi al-Lughah. Qahirah: Maktabah al-Anjalu al-Misriyyah.

Hilal, Abdu al-Ghaffar.(1996). Aswat al-Lughah al-Arabiyyah. Thaba'ah Tsaniyyah. Qahirah: Maktabah Wahbah.

Ibnu Jinni, Abu Usman. (1954). Sir al-Shina'ah. Thaba'ah Ula. Qahirah: Musthafa al-Saqa, Musthafa al-Babi al-Halbi.

Istitiyyah, Samir. (2003). Al-Aswat al-Lughawiyyah. Thaba'ah Ula. Oman: Dar Wail li al-Nasyr.

Sibawaih, Abu Basyar. (1975). Al-Kitab al-Juz al-Rabi'. Thaba'ah Tsaniyyah. Tahqiq: Abdu al-Salam Harun.

Syahin, Abdu al-Shabur. Al-Manhaj al-Shauti li al-Bunyah al-Arabiyyah. Qahirah: Maktabah alSyabab.

Syumuli, Qustandi. (1986). Madkhal ila Ilm al-Lughah al-Hadits. Thaba'ah Tsaniyyah. Al-Quds.

Umar, Ahmad Mukhtar. (1976). Dirasah al-Shaut al-Lughawi. Thaba'ah Ula. Qahirah: Alim al-Kutub. 
LiNGUA Vol. 11, No. 1, Juni 2016 •ISSN 1693-4725 • e-ISSN 2442-3823

Wafi, Ali Abdu al-Wahid. Ilm al-Lughah. Thaba'ah Rabi'ah. Qahirah: Maktabah Nahdhah Misr. 